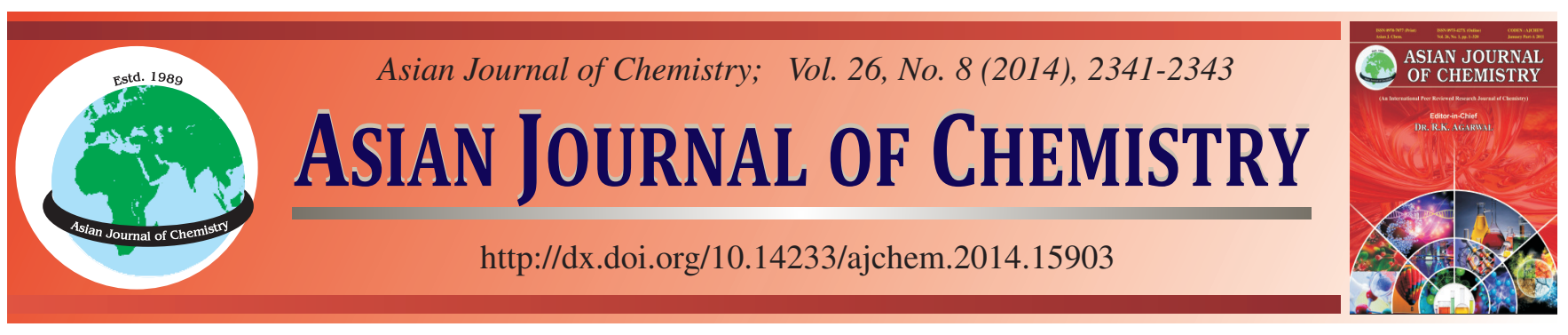

\title{
A Supramolecular Copper(II) Complex with an Asymmetric Salamo-Type Ligand: Synthesis and Crystal Structure
}

\author{
W.-K. Dong*, Y. BAI, L.-S. Zhang, X.-Y. Dong, M.-M. ZhaO and G. Li
}

School of Chemical and Biological Engineering, Lanzhou Jiaotong University, Lanzhou 730070, P.R. China

*Corresponding author: E-mail: dongwk@126.com

\begin{abstract}
A supramolecular mononuclear $\mathrm{Cu}(\mathrm{II})$ complex, $[\mathrm{CuL}]$, has been synthesized via the complexation of copper(II) acetate monohydrate with 4-chloro -4',6'-dibromo-2,2'-[ethylenediyldioxybis(nitrilomethylidyne)]diphenol $\left(\mathrm{H}_{2} \mathrm{~L}\right)$ in methanol/acetone solution and characterized by X-ray diffraction method. X-Ray crystallographic analysis reveals that the $\mathrm{Cu}(\mathrm{II})$ atom is tetra-coodinated by $\mathrm{N}_{2} \mathrm{O}_{2}$ donor atoms from the asymmetic Salamo-type $\mathrm{L}^{2-}$ unit, resulting in an almost regular distorted square-planar geometry. With the help of intermolecular $\mathrm{C} 2-\mathrm{H} 2 \mathrm{~A} \cdots \mathrm{O} 2$ and $\mathrm{C} 2-\mathrm{H} 2 \mathrm{~B} \cdots \mathrm{Br} 1$ hydrogen-bonding interactions, a self-assembled 2D-layer supramolecular structure is formed.
\end{abstract}

Keywords: Asymmetric Salamo-type Ligand, Cu(II) Complex, Synthesis, Crystal Structure.

\section{INTRODUCTION}

$\mathrm{N}_{2} \mathrm{O}_{2}$ type ligands such as Salen, which are easily obtained by the reaction of salicylaldehyde with diamines, coordinate to $d$-block transition metals in a tetradentate fashion to afford stable mononuclear complexes ${ }^{1}$. Symmetric Salamo-type ligands and their complexes have also attracted much attention for their novel structures and spectral characteristics ${ }^{2,3}$, especially for their excellent photoluminescence ${ }^{4}$ and interesting magnetic properties ${ }^{5}$. Furthermore, $\mathrm{Cu}$ (II) complexes with symmetric Salamo-type ligands have been studied for their fluorescence properties ${ }^{6}$.

Compared with symmetric Salamo-type ligands, a selective synthesis of asymmetrical Salamo-type ligands is important because the electronic and steric effects of the ligands on Salamo metal-assisted catalysis may be controlled by introduction of different substituents into the two benzene rings ${ }^{7}$. The asymmetric configuration would offer opportunities for structural variation and infinite coordination polymers, which would be expected to lead to novel characteristics. Further, this change could create better ways to control polymerizaton in the context of the infinite coordination polymer structures (different functionality allows to use different metals in the polymerization process $)^{8}$. It has been reported that metal complexes derived from asymmetric Salen ligands sometimes exhibit better enantioselectivities when compared with their symmetric counterparts ${ }^{9}$. In order to study the structural features and spectral characteristics of transition metal complexes with asymmetric Salamo-type ligands, we herein report a supramolecular complex [CuL] with an asymmetric Salamo-type ligand 4-chloro-4',6'-dibromo-2,2'-[ethylenediyldioxybis(nitrilomethylidyne)]diphenol $\left(\mathrm{H}_{2} \mathrm{~L}\right)$.

\section{EXPERIMENTAL}

3,5-Dibromo-2-hydroxybenzaldehyde ( $\geq 99 \%)$ and 2hydroxy-5-chlorobenzaldehyde ( $\geq 99 \%$ ) were purchased from Alfa Aesar and used without further purification. 1,2-Bis(aminooxy)ethane was synthesized according to an analogous method reported earlier ${ }^{10,11}$. The others are the same as literature early ${ }^{12}$.

Synthesis of $\mathbf{H}_{2} \mathbf{L}$ : The major reaction steps involved in the synthesis of $\mathrm{H}_{2} \mathrm{~L}$ are given in Scheme-I. $\mathrm{H}_{2} \mathrm{~L}$ was synthesized according to an analogous method reported earlier ${ }^{13}$. Yield 80.8 \%. m.p. 403-404 K. Anal. Calcd. for $\mathrm{C}_{16} \mathrm{H}_{13} \mathrm{~N}_{2} \mathrm{O}_{4} \mathrm{Br} 2 \mathrm{Cl}(\%)$ : C, 39.02; H, 2.66; N, 5.69. Found: C, 39.28; H, 2.42; N, 5.43.

Synthesis of $\mathrm{Cu}(\mathrm{II})$ complex: A solution of $\mathrm{Cu}(\mathrm{OAc})_{2} \cdot \mathrm{H}_{2} \mathrm{O}$ (1.99 mg, $0.01 \mathrm{mmol})$ in methanol $(2 \mathrm{~mL})$ was added dropwise to a solution of $\mathrm{H}_{2} \mathrm{~L}$ ( $\left.4.93 \mathrm{mg}, 0.01 \mathrm{mmol}\right)$ in acetone $(2 \mathrm{~mL})$ at room temperature. The colour of the mixing solution turned to dark-green immediately, then stirred for $1 \mathrm{~h}$ at room temperature. The mixture was filtered off and the filtrate was allowed to stand at room temperature for about two days, the solvent was partially evaporated and obtained green block-like single crystals suitable for X-ray crystallographic analysis. Anal. calcd. for $\mathrm{C}_{16} \mathrm{H}_{11} \mathrm{~N}_{2} \mathrm{O}_{4} \mathrm{Br}_{2} \mathrm{ClCu}(\%)$ : C,34.68; H, 2.00; N, 5.06; $\mathrm{Cu}, 11.47$. Found: C, 34.83; H, 2.08; N, 4.95; Cu, 10.98. 

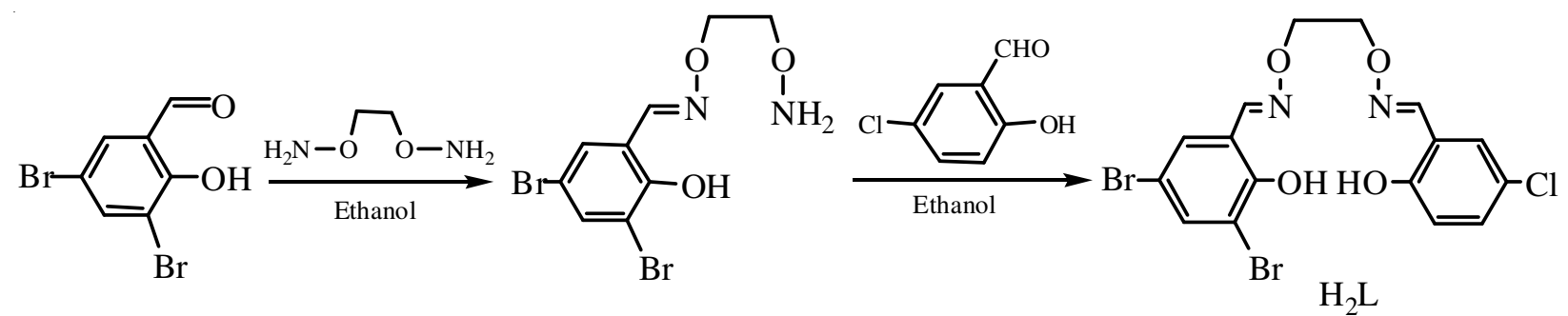

Scheme-I: Synthetic route to 4-chloro-4',6'-dibromo-2,2'-[ethylenediyldioxybis(nitrilomethylidyne)]diphenol $\left(\mathrm{H}_{2} \mathrm{~L}\right)$

X-Ray structure determination: The X-Ray structure determination is the same as literature early ${ }^{12}$. The crystal data and structure refinement for the $\mathrm{Cu}$ (II) complex are given in Table-1.

\begin{tabular}{|c|c|}
\hline \multicolumn{2}{|c|}{$\begin{array}{c}\text { TABLE-1 } \\
\text { CRYSTAL DATA AND STRUCTURE REFINEMENT } \\
\text { FOR Cu(II) COMPLEX }\end{array}$} \\
\hline Empirical formula & $\mathrm{C}_{16} \mathrm{H}_{11} \mathrm{~N}_{2} \mathrm{O}_{4} \mathrm{Br}_{2} \mathrm{ClCu}$ \\
\hline Formula weight & 554.08 \\
\hline Temperature (K) & 298(2) \\
\hline Wavelength $(\AA)$ & 0.71073 \\
\hline Crystal system & Monoclinic \\
\hline Space group & $\mathrm{P} 2(1) / \mathrm{n}$ \\
\hline Cell dimensions, $(\AA$, deg $)$ & $\begin{array}{r}\mathrm{a}=13.7287(12), \mathrm{b}= \\
6.7822(5) \\
\mathrm{c}=19.1223(16), \beta= \\
109.392(2)\end{array}$ \\
\hline Volume $\left(\AA^{3}\right)$ & $1679.5(2)$ \\
\hline$Z$ & 4 \\
\hline Density (calculated) $\left(\mathrm{mg} / \mathrm{m}^{3}\right)$ & 2.191 \\
\hline Absorption coefficient $\left(\mathrm{mm}^{-1}\right)$ & 6.244 \\
\hline$F_{(000)}$ & 1076 \\
\hline Crystal size (mm) & $0.35 \times 0.14 \times 0.09$ \\
\hline Index ranges & $\begin{array}{c}-16 \leq \mathrm{h} \leq 16,-8 \leq \mathrm{k} \leq 7 \\
-17 \leq 1 \leq 22\end{array}$ \\
\hline Reflections collected & $8116 / 2945[\mathrm{R}(\mathrm{int})=0.0975]$ \\
\hline Independent reflections & 1747 \\
\hline Data/restraints/parameters & $2945 / 0 / 235$ \\
\hline Goodness of fit indicator & 1.070 \\
\hline $\mathrm{R}[\mathrm{I}>2 \sigma(\mathrm{I})]$ & $\mathrm{R}_{1}=0.0643, \mathrm{wR}_{2}=0.1045$ \\
\hline Largest diff. peak and hole $\left(\mathrm{e} \AA^{-3}\right)$ & 2.404 and -1.130 \\
\hline
\end{tabular}

\section{RESULTS AND DISCUSSION}

Crystal structure of $\mathrm{Cu}(\mathrm{II})$ complex: ORTEP representation of the $\mathrm{Cu}$ (II) complex is shown in Fig. 1. Selected bond lengths and angles are listed in Table-2.

$\mathrm{X}$-ray crystallographic analysis reveals that the $\mathrm{Cu}$ (II) complex crystallizes in the monoclinic system, space group $\mathrm{P} 2(1) / \mathrm{n}$ with $\mathrm{Z}=4$. The molecular structure of the $\mathrm{Cu}(\mathrm{II})$ complex consists of one $\mathrm{Cu}(\mathrm{II})$ atom and one $\mathrm{L}^{2-}$ unit. As shown in Fig. 1, the Salamo-type $\mathrm{L}^{2-}$ moiety in the $\mathrm{Cu}$ (II) complex is not planar, but has a twisted geometry. The $\mathrm{Cu}(\mathrm{II})$ ion is tetracoordinated in a cis $-\mathrm{N}_{2} \mathrm{O}_{2}$ geometry by two oxime nitrogen (N1 and N2) atoms and two phenoxo oxygen (O3 and O4) atoms from the deprotonated $\mathrm{L}^{2-}$ unit. The dihedral angle between the coordination planes of N1-Cu1-O3 and N2-Cu1$\mathrm{O} 4$ is $27.97(4)^{\circ}$. Consequently the coordination sphere can be described as a slight distortion toward tetrahedral geometry from the square planar structure. Furthermore, the deviation

\begin{tabular}{cccc}
\hline \multicolumn{4}{c}{ TABLE-2 } \\
SELECTED BOND LENGTHS $(\AA)$ AND ANGLES $\left(^{\circ}\right)$ \\
FOR THE Cu(II) COMPLEX \\
\hline Bond & Lengths & Bond & Lengths \\
\hline Cu1-O3 & $1.859(6)$ & Cu1-N2 & $1.916(9)$ \\
Cu1-O4 & $1.878(7)$ & Cu1-N1 & $1.966(8)$ \\
\hline Bond & Angles & Bond & Angles \\
\hline O3-Cu1-O4 & $87.6(3)$ & C3-N1-Cu1 & $124.8(8)$ \\
O3-Cu1-N2 & $161.9(4)$ & O1-N1-Cu1 & $90.1(4)$ \\
O4-Cu1-N2 & $90.4(3)$ & C10-N1-Cu1 & $128.2(7)$ \\
O3-Cu1-N1 & $90.8(3)$ & O2-N2-Cu1 & $118.9(6)$ \\
O4-Cu1-N2 & $157.4(4)$ & C5-O3-Cu1 & $130.3(6)$ \\
N2-Cu1-N1 & $97.8(3)$ & C12-O4-Cu1 & $130.5(7)$ \\
\hline
\end{tabular}

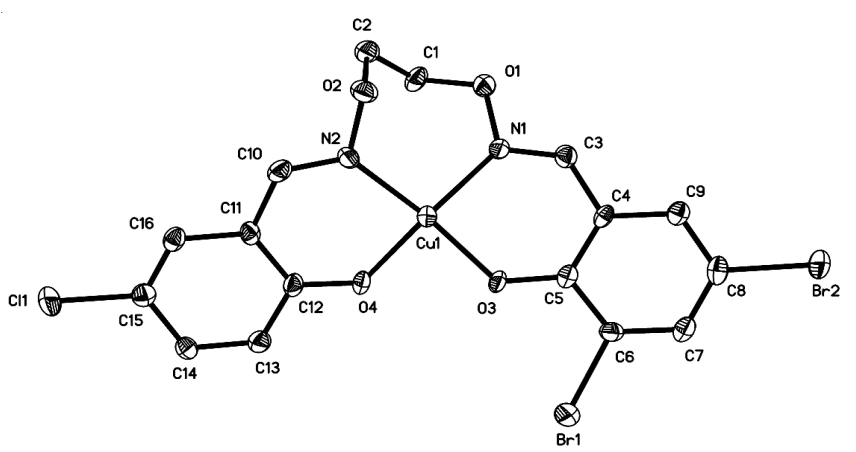

Fig. 1. Molecule structure of the $\mathrm{Cu}(\mathrm{II})$ complex with atom numbering scheme. Displacement ellipsoids for non-hydrogen atoms are drawn at $30 \%$ probability level

of $\mathrm{Cu} 1$ atom from the $\mathrm{N}_{2} \mathrm{O}_{2}$ coordination plane is $0.042(2) \AA$ and the four donor $(\mathrm{N} 1, \mathrm{~N} 2, \mathrm{O} 3$ and $\mathrm{O} 4)$ atoms from their mean plane are 0.299(2), -0.303(4), -0.344(3) and 0.348(1) $\AA$, respectively. In addition, the ethylenedioxime carbons (C1 and $\mathrm{C} 2$ ) atoms in the $\mathrm{Cu}(\mathrm{II})$ complex are buckled asymmetrically from the $\mathrm{Cu} 1 \mathrm{~N} 1 \mathrm{~N} 2$ plane, with the displacement for C1 being $0.1414(4) \AA$ toward the plane and for $\mathrm{C} 2$ being only $0.483(3) \AA$ in the same direction. It is noteworthy that the $\mathrm{Cu}-\mathrm{N}$ bond lengths, $1.916(9)$ and 1.966(8) $\AA$, are considerably longer than the $\mathrm{Cu}-\mathrm{O}$ bond lengths, $1.859(6)$ and 1.878(7), respectively, which is similar to those of previously reported Salamo-type complex ${ }^{13}$.

Intermolecular interactions of the $\mathbf{C u}$ (II) complex: The hydrogen bond data are summarized in Table-3. In the crystal structure, intermolecular $\mathrm{C} 2-\mathrm{H} 2 \mathrm{~B} \cdots \mathrm{Br} 1$ hydrogen bond, is formed between the $-\mathrm{C} 2 \mathrm{H} 2 \mathrm{~B}$ group from the $\mathrm{O}$-alkyl chain of $\mathrm{L}^{2-}$ unit and bromo $(\mathrm{Br} 1)$ atom of the benzene ring. The intermolecular $\mathrm{C} 2-\mathrm{H} 2 \mathrm{~B} \cdots \mathrm{Br} 1$ hydrogen bond links two neighboring molecules into an infinite 1D chain supramolecular structure along the $b$ axis, as illustrated in Fig. 2. Furthermore, this linkage is further stabilized via intermolecular $\mathrm{C} 2-\mathrm{H} 2 \mathrm{~A} \cdots \mathrm{O} 2$ 
TABLE-3

DATA FOR HYDROGEN-BONDING INTERACTIONS $\left(\AA{ }^{\circ}{ }^{\circ}\right)$

\begin{tabular}{cccccc}
\hline $\mathrm{D}-\mathrm{H} \cdots \mathrm{A}$ & $\mathrm{d}(\mathrm{D}-\mathrm{H})$ & $\mathrm{d}(\mathrm{H} \cdots \mathrm{A})$ & $\mathrm{d}(\mathrm{D} \cdots \mathrm{A})$ & $\angle \mathrm{D}-\mathrm{H} \cdots \mathrm{A}$ & Symmetry code \\
\hline $\mathrm{C} 2-\mathrm{H} 2 \mathrm{~A} \cdots \mathrm{O} 2$ & 0.97 & 2.56 & $3.453(6)$ & 154 & $2-\mathrm{x}, 3-\mathrm{y},-\mathrm{z}$ \\
$\mathrm{C} 2-\mathrm{H} 2 \mathrm{~B} \cdots \mathrm{Br} 1$ & 0.97 & 2.93 & $3774(6)$ & 147 & $5 / 2-\mathrm{x},-1 / 2+\mathrm{y}, 1 / 2-\mathrm{z}$ \\
\hline
\end{tabular}

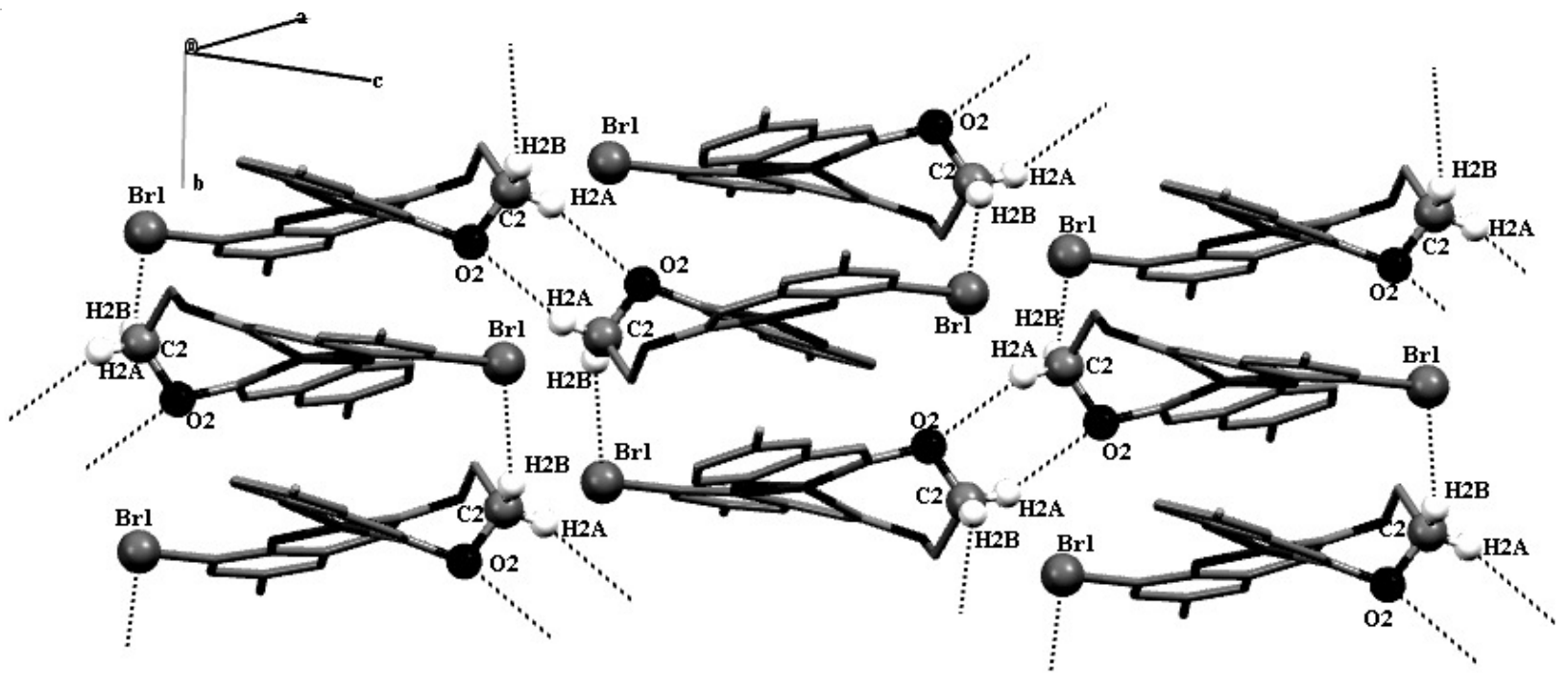

Fig. 3. (Color online). View of the 2D layer motif (hydrogen atoms, except those forming hydrogen bonds, are omitted for clarity)

hydrogen bonds. Thus, every $\mathrm{Cu}(\mathrm{II})$ complex molecule links three other molecules into an infinite 2D-layer supramolecular structure on the bc crystallographic plane via intermolecular $\mathrm{C} 2-\mathrm{H} 2 \mathrm{~B} \cdots \mathrm{Br} 1$ and $\mathrm{C} 2-\mathrm{H} 2 \mathrm{~A} \cdots \mathrm{O} 2$ hydrogen-bonding interactions $^{14}$ (Fig. 3).

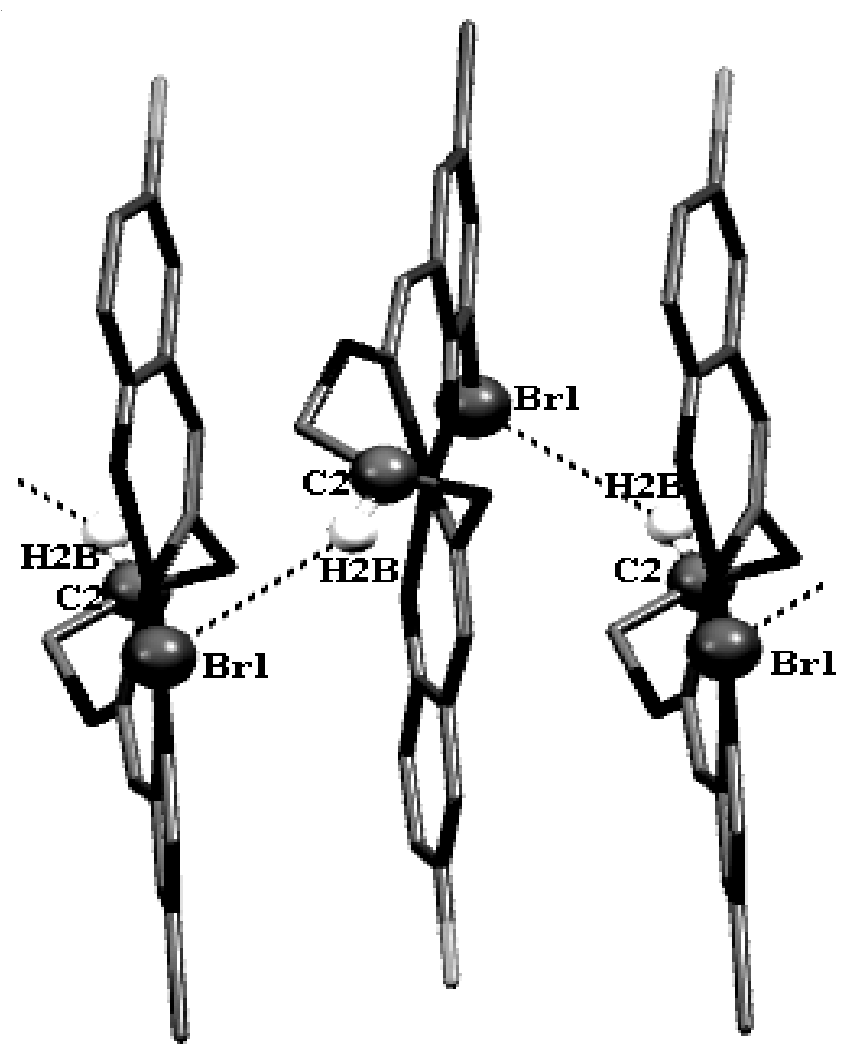

\section{ACKNOWLEDGEMENTS}

This work was supported by the Foundation of Gansu Province Traffic Transportation Dust Control Engineering Technology Research Center (513001-1), the Fundamental Research Funds for the Gansu Province Universities (212086) and the science and technology support funds of Lanzhou Jiaotong University (ZC2012003), which are gratefully acknowledged.

\section{REFERENCES}

1. P. Pfeiffer, E. Breith, E. Lübbe and T. Tsumaki, Liebigs Ann. Chem., 503, 84 (1933); (b) P. Pfeiffer, T. Hesse, H. Pfitzner, W. Scholl and H. Thielert, J. Prakt. Chem., 149, 217 (1937).

2. S. Akine, T. Taniguchi and T. Nabeshima, Chem. Lett., 682 (2001).

3. L. Xu, Y.P. Zhang and Y.X. Sun, Chinese J. Inorg. Chem., 23, 1999 (2007).

4. W.K. Dong and Y.J. Ding, Cryst. Res. Technol., 43, 321 (2008).

5. S. Akine, W.K. Dong and T. Nabeshima, Inorg. Chem., 45, 4677 (2006).

6. W.K. Dong, J.G. Duan, Y.H. Guan, J.Y. Shi and C.Y. Zhao, Inorg. Chim. Acta, 362, 1129 (2009).

7. S. Akine, T. Taniguchi, W.K. Dong, S. Masubuchi and T. Nabeshima, J. Org. Chem., 70, 1704 (2005).

8. Y.M. Jeon, J. Heo and C.A. Mirkin, Tetrahedron Let., 48, 2591 (2007).

9. G.J. Kim and J.H. Shin, Catal. Lett., 63, 83 (1999).

10. W.K. Dong, Y.X. Sun, G.H. Liu, L. Li, X.Y. Dong and X.H. Gao, Z. Anorg. Allg. Chem., 638, 1370 (2012).

11. S. Akine, T. Matsumoto, S. Sairenjia and T. Nabeshima, Supramol. Chem., 23, 106 (2011).

12. W.K. Dong, K.Q. Li, Y. Zhang, L. Xu, L. Wang and X.Y. Dong, Asian J. Chem., 25, 4398 (2013).

13. W.K. Dong, S.J. Xing, Y.X. Sun, L. Zhao, L.Q. Chai and X.H. Gao, J. Coord. Chem., 65, 1212 (2012).

14. H.L. Wu, X.C. Huang, J.K. Yuan, F. Kou, F. Jia, B. Liu and Y. Bai, Z. Naturforsch., 66b, 1049 (2011).
Fig. 2. (Color online). View of the 1D chain motif of the complex units along the b-axis (hydrogen atoms, except those forming hydrogen bonds, are omitted for clarity) 